\title{
Urban Consumer Attitudes to Fresh Produce Safety in
}

\section{China}

Brian J. Revell

Harper Adams University, Newport, Shropshire, TF10 8NB, United Kingdom

\begin{abstract}
The objective of this study was to explain the determinants of the fresh vegetables purchase decision by Chinese urban consumers in Beijing including awareness and attitudes to food safety, and their willingness to pay (WTP) more for specific safety characteristics when buying fresh vegetables. The research rationale arises out of a history of food safety scares and scandals in China, and a national government response to promote quality assurance and safety through labelling. The primary hypothesis was that an understanding of food safety systems and product labelling, and trust in supply chain integrity would be key determinants in consumer willingness to purchase and pay more for safety assured vegetables. Based on a questionnaire survey of consumers in Beijing, the analysis found that the major factors underlying the purchase decision of fresh vegetables were product freshness, convenience and competitive price rather than assured product labelling. The decisions whether to purchase assurance-labelled vegetables and WTP more for chemical residue-free product were analysed by binomial and ordinal multinomial logit modelling respectively. It revealed a WTP moreof between $20 \%$ and $40 \%$. Monthly household income was a key determinant of both quality assured product and WTP, together with degree of concern over residues, trust in retailer and assurance labels and place of purchase. The results suggest much still remains to be done to build trust though rigorous monitoring and enforcement of food safety standards to improve supply chain integrity and consumer confidence.
\end{abstract}

Key words: Food safety, fresh produce, consumer preferences, China, logit modelling, WTP.

\section{Introduction}

Research has provided convincing evidence to support the premise that diets rich in vegetables confer health benefits and may even be protective against the risk of different types of cancers [1, 2]. However, at the same time vegetables have increasingly been recognized as vectors for food-borne illnesses [3-5] that can affect consumers in both domestic and export markets.

Consumers in different countries or regions place differing levels of importance on the many quality characteristics of vegetables. Simonne and Behe [6] found that price and variety were the two main attributes of importance to tomato consumers in the USA, with younger less price-sensitive consumers placing more importance on other attributes such as

Corresponding author: Brian J. Revell, 2015-16 President of the Agricultural Economics Society, Emeritus Professor, research fields: agricultural and food economics. production methods. Low price and organic certification for carrots were preferred choices of consumers in Brazil [7]. The key factors influencing purchase of "safe vegetables" in Thailand were income, pesticide residue awareness, education and age [8], whilst factors affecting preferences and choice of dried mushrooms in Taiwan were health, convenience, weight control, food safety, and familiarity [9]. Italian consumers' willingness to pay (WTP) for pesticide-free fresh fruit and vegetables was significantly and positively related to income and risk concerns and negatively related to education [10].

Over recent years there have been a range of prominent food safety scandals in China with both national and international repercussions. These include inter alia the 2008 melamine protein contaminant scandal in liquid milk, where even now the ramifications resurface periodically in the food market through the reappearance of residual illegal contaminated stocks, clenbuterol in animal feeds, and 
recycled waste or "gutter" cooking oils recovered from drains. There have also been safety issues relating to fruit and vegetables, dating from as early as 2001-02 concerning pesticide residues on Chinese exports of spinach to Japan, adulterated pickled vegetables, excess residues on vegetables exported to Hong Kong and poisonous mushrooms in Beijing [11-15]. Moreover a public opinion survey conducted by the Public Opinion Research Laboratory and Crisis Management of Shanghai Jiaotong University reported in Ref. [16] found clear evidence that food safety still remains the primary public concern in China.

The Government and industry response to food safety problems has been both through the development and continual strengthening of Food Safety legislation, and through the development of certification or food label schemes. At present, there are three predominant quality-assurance labels for agricultural produce in China, viz. Pollution-Free, Green Food, or Organic products, with each meeting different quality standards. In addition there are also regional produce labels and a Quality-Safety label introduced in 2008 mainly applicable to processed products.

Pollution-Free agricultural product standards, which came into effect in 2001, are compulsory, and are a direct result of raised public health issues. They are based on four criteria:

- Field environmental quality standards, including quality of air, water and soil;

- Production technology standards, including quality controls of production inputs;

- Product standards, including primary and processed product standards;

- Packaging, labelling, storage and transportation standards.

Green Food is categorized into AA level and A level, whose quality standards should meet standards set by Food and Agriculture Organization and World Health Organization, and the use of chemical compounds and other poisonous materials are restricted or forbidden. Green Food dates from 1990 [17] and encompasses four environmental criteria:

- The production area should meet the highest grade of atmospheric standards;

- Residues of heavy metals are restricted in irrigation water and soil;

- Processing water must meet National Drinking Water Standards;

- Applications of agro-chemicals are restricted and regulated, and some banned.

Organic Food should meet the basic standards set by the European Union and the International Federation of Organic Agriculture Movement (IFOAM), which completely prohibits any use of chemical substance during agricultural production or the use of genetic engineering technologies. The Organic Food Standards were first set in 1991 and products must also meet the following criteria:

- raw materials should derive from organic agricultural production systems or wild natural products;

- products must remain in strict compliance with the organic food processing, packaging, storage, transportation requirements throughout the supply chain;

- the production process and holding must be approved by an independent body of organic food certification.

Studies on Chinese consumers' attitudes to food safety and WTP for safe food or quality labelled produce are not extensive, though now becoming more numerous given that food safety concerns have risen sharply on the consumer and government's agendas. It is not surprising therefore that more attention is now being paid to Chinese consumers' knowledge, concerns and responses to food safety issues, as exemplified by studies on meat safety [18], milk products [19] and vegetables [20-22] together with those examining attitudes and acceptance of genetically modified (GM) food products [23]. 
An understanding of both of consumer's perceptions and attitudes toward vegetable safety and the determinants and their WTP for safety assurance should help both in shaping the future development of the vegetable supply chain in China and focusing on those standards which have marketable value. It can communicate to chain participants those risks consumers recognize and their WTP most to avoid, and identify the factors necessary to maintain consumer confidence and trust [24, 25].

Whilst there have been a number of published studies of the WTP for green vegetables in the Chinese literature, they have not been published in English language journals. Furthermore, they have been largely based on surveys conducted in second tier cities in central China such as Wuhan or Nanjing, or have focused solely on WTP for a specific quality or safety label certification [26-32]. The unique contribution of this paper was to extend the geographic scope of such studies to focus on more prosperous and populous east coast urban China, to include a wider range of safety certifications, and to capture any attitudinal changes of consumers to food safety which might have been prompted by subsequent food scare scandals. It set out to identify a range of potential factors that might influence consumers' purchasing behavioursof fresh vegetables, in order to determine those that critically affect both their purchasing of certified or labelled product, and their WTP to avoid of range of potential food safety hazards.

\section{Materials and Methods}

This section describes the process by which the data were obtained and the statistical modelling methodologies utilised. The statistical analysis presented was based on data generated from 319 responses to face-to face questionnaire-based interviews across all districts in Beijing, this being the largest city sample as part of a wider pan-China study of over 1,500 urban city respondents. Respondents wereselected as being the main household food shoppers. Fig. 1 summarises and presents a simplified rationale underlying the structure of the questionnaire

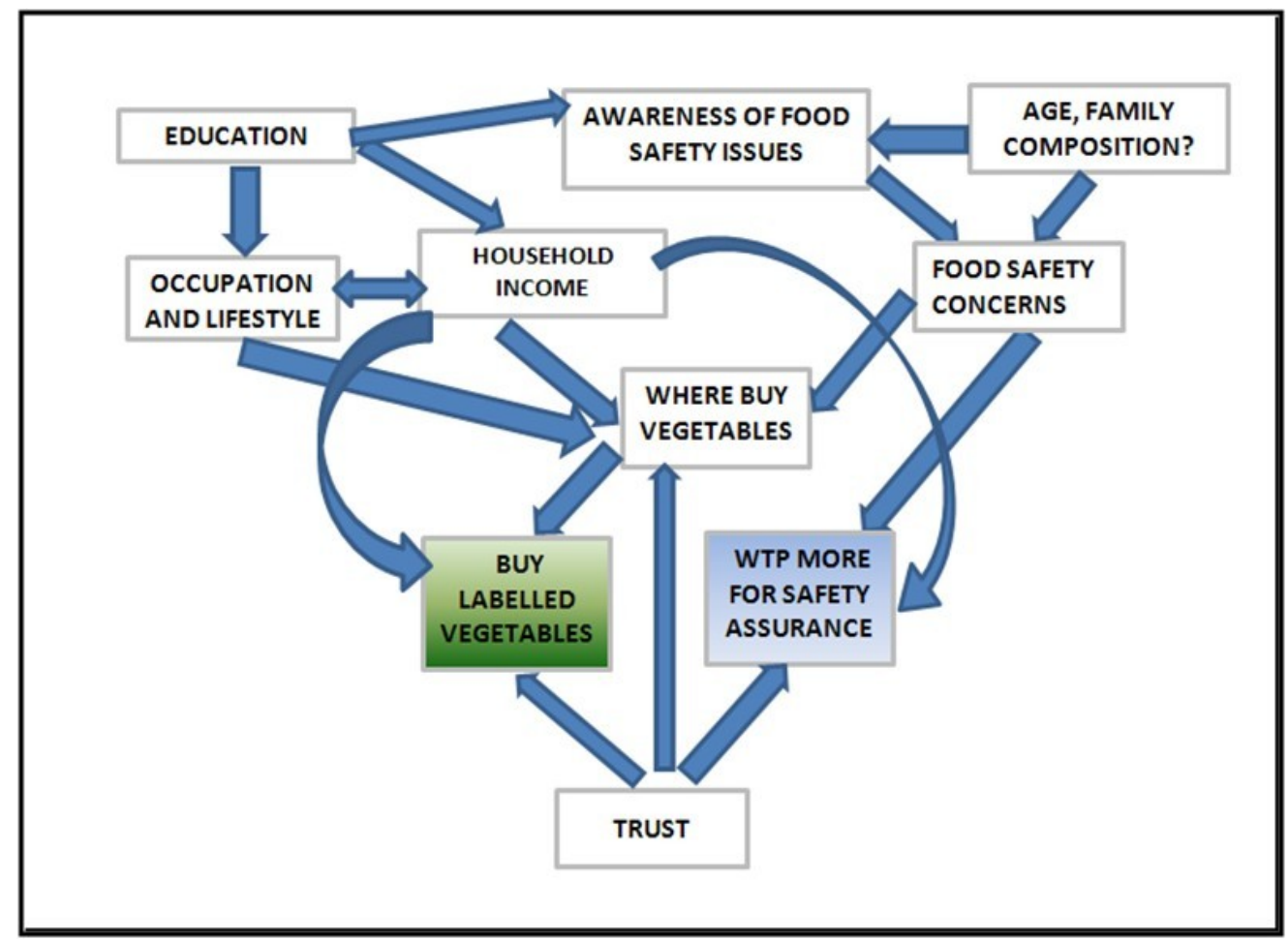

Fig. 1 Purchase determinants of assured vegetables and WTP more for assurance. 
to consumers and the basis for the subsequent statistical modelling analysis of their decisions in section 3 of the paper.

The underlying decision system in Fig. 1 is unlikely to be linear, and there are both feedbacks and latent variables within the system, which can be characterised and elicited through responses to appropriate questions, though not necessarily definitively. It was hypothesised that level of education would be a key factor, either directly or indirectly affecting both whether consumers purchased quality-safety assured vegetables and whether they were WTP more for them. It might also condition the degree of awareness of consumers about food safety issues, and exert a significant influence on the level of their household income, occupation and lifestyle. Household income was also thought likely to affect whether consumers would buy the generally more expensive quality-safety labelled vegetables compared with non-quality assured produce. Also, income could affect where vegetables were predominantly purchased, given that assurance labelled vegetables were only available in supermarkets and hence generally would require car ownership if purchases were to be made there as their location may be some distance from that of the household.Conversely, less affluent consumers might most probably purchase in local neighbourhood wet-markets.Age and possibly family composition (especially the presence of young children) might also affect awareness of food safety, exert a strong influence on food safety concerns, and hence on the WTP more for assured safe food. Finally, trust in the retail outlet, and trust in the integrity of the standards of compliance and enforcement with the quality label criteria would also be expected a priori to affect both willingness to purchase and WTP more.

The questionnaire was designed to elicit information relating to these elements of the consumer purchase decision. It explored inter alia purchase frequency, place of purchase, accessibility and reasons for choice of place of purchase, trust in place of purchase to sell safe vegetables and labels, awareness of safety issues such as traceability, and WTP extra for vegetables either guaranteed free from specific health hazards or bearing specific quality-safety labels. Socio-economic household characteristics relating to gender, age, education level, marital status, occupation, monthly incomeand household compositionwere recorded as potential contributors to the decision process. With the exception of household composition and income measured in Chinese Renminbi (RMB) ranges, the variables in analysis were predominantly ordinal and/or categorical in nature.

There is a range of approaches to modelling consumer choice and WTP. Although conjoint analysis offers the advantage of estimating the trade-offs between product attributes, including price and quality-safety features there are significant limitations on the range of product attributes which can be included if the choice set is to be manageable for consumers to rank their preferences. From a practical viewpoint, there were also a number of drawbacks to using conjoint analysis in the Chinese context, including complexity of explanation and interview not with standing native Chinese interviewers, a cultural un-willingness of consumers to participate readily, and the unfamiliarity of many Chinese consumers with concepts of assurance, labels and safety. Wang et al. [19] used both consumer survey for WTP analysis and hedonic pricing based on store survey of prices to evaluate the partial price of a safety attribute in milk in Beijing. Zhou and Peng [31] and Dai et al. [29] used logit models to explain label purchase whilst He et al. [32] estimated an ordered probit model.

Logit analysis is thus well established in the literature for binomial and multinomial choice modelling. In Eq. (1) it is hypothesised that the variable $y$ can take on only two values, namely 0 or 1 , where for example for the purchase of labelled vegetables, $y=0$ signifies "do not buy" and $=1$ 
signifies "buy", and the vector $\mathrm{X}$ is a set of independent explanatory variables which determine $y$.

$$
\mathrm{y}=\beta \mathrm{X}+\varepsilon
$$

In the logistic model, $\mathrm{E}(\mathrm{ylX})=\operatorname{Pr}(\mathrm{ylX})$ where the cumulative density function is given by

$$
\operatorname{Pr}(y \mid X)=\frac{e^{\beta X}}{\left(1+e^{\beta X}\right)}
$$

The logit transformation linearizes the response function such that:

$$
\ln \left(\frac{\operatorname{Pr}(\mathrm{y} \mid \mathrm{X})}{1-\operatorname{Pr}(\mathrm{y} \mid \mathrm{X})}\right)=\beta \mathrm{X}
$$

Eq. (3) defines the odds ratio, the probability of buying to not buying labelled vegetables given the variables $\mathrm{X}$.

Whilst the binomial logit model can analyse mutually exclusive choices with 2 outcomes, the multinomial logit model extends to $k$ multiple outcomes, where $\operatorname{Pr}(1)+\operatorname{Pr}(2)+\ldots \operatorname{Pr}(k)=1$ and $k-1$ equations are estimated [33]. In the context of WTP studies, where we offered the respondents a range of discrete but incremental additional percentage premiums to pay for specific safety features, the ordinal multinomial logit is appropriate. By way of illustration, with 3 alternatives to select: $i=1,2,3$

$$
\operatorname{Pr}\left(\mathrm{y}_{\mathrm{j}}=i\right)=\frac{\mathrm{e}^{\mathrm{X} \beta(i)}}{\left(\mathrm{e}^{\mathrm{X} \beta(1)}+\mathrm{e}^{\mathrm{X} \beta(2)}+\mathrm{e}^{\mathrm{X} \beta(3)}\right)}
$$

and where for example, the odds ratio of $y=2$ to base category $y=1$ is given by $\mathrm{e}^{\mathrm{x} \beta(2)}$.

In the ordered multinomial logit model the probability of an outcome is calculated as a linear function of the independent variables plus a set of cut points $\mathrm{C}$ which divide the ordinal categories of the dependent variable such that

$$
\operatorname{Pr}\left(\mathrm{y}_{\mathrm{j}}=i\right)=\operatorname{Pr}\left(\mathrm{C}_{i-1}<(\beta \mathrm{X}+\varepsilon)<\mathrm{C}_{i}\right)
$$

Eq. (5) can be rewritten as:

$$
\operatorname{Pr}\left(\mathrm{y}_{\mathrm{j}}=i\right)=\frac{1}{\left[1+\left(\mathrm{e}^{-\mathrm{C}_{i}+\mathrm{X \beta}}\right)\right]}-\frac{1}{\left[1+\left(\mathrm{e}^{-\mathrm{C}_{i-1}+\mathrm{X \beta}}\right)\right]}
$$

The ordered logit model embodies a proportional odds or parallel slopes assumption which requires that the separate equations for each category differ only in their intercepts (i.e. cut points). This can be tested by comparing the fit of the ordinal multinomial logit model to that of the multinomial.

\section{Results and Discussion}

It is first worthwhile outlining a few of the initial fundamental findings from the survey data before focusing specifically on the purchase analysis as these formed the basis forselection of the independent variables entering into the logit models explaining the determinants of consumer purchase of quality and safety assured vegetables and their WTP extra for such assurances. Over half of respondents walked to buy vegetables, with $29 \%$ cycling to shops. Just over half purchased daily, with a further $38 \%$ buying every 2 or 3 days. Regarding main place of purchase, $22 \%$ bought their vegetables at a traditional wet or street market, $26 \%$ at farmers' markets, and $32 \%$ at supermarkets with the remaining $20 \%$ buying at local community fruit and vegetable shops or morning and evening markets. The key reasons given for choice of purchase location were "product freshness" (60\%), "closeness to home" (59\%), "competitive price" (54\%) and "range of choice" (50\%). Hence, convenience was a determinant of where they bought. Only $30 \%$ of respondents cited "assured product quality and safety" as an important reason. When asked to score the safety of the vegetables bought, ranging from $100 \%$ to $20 \%$ or below, only $5 \%$ felt their vegetable purchases were completely safe. Nearly $60 \%$ rated their vegetables as between $70 \%-80 \%$ safe, thus indicating a predominant lack of complete confidence in the safety of fresh vegetables. In terms of Beijingers' awareness of traceability as a part of a food safety system, $60 \%$ of respondents had never heard of it. Less than $1 \%$ professed to understand what "traceability" was.

In identifying the relative importance of factors of concern to Beijing consumers when buying vegetables, the survey distinguished between intrinsic product quality attributes, viz. price, freshness, taste, appearance, variety and nutrition, and extrinsic factors associated with the dimensions of safety and 
assurance, viz. region of production, traceability, chemical residues, artificial fertilisers, genetic modification, and quality/safety assurance labels. Initial analysis indicated the former were of greatest concern $^{1}$ to Chinese consumers, with freshness $(87 \%$ of respondents), nutrition (74\% of respondents) and taste $(70 \%$ of respondents) of most importance. The assurance and safety attributes appeared to be of lesser concern to consumers, with chemical residues the most important to $56 \%$ respondents, and fewer than half (47\%) citing the absence of an assurance label as of concern. Indeed, when asked to prioritise the single most important factor determining their purchase of vegetables, $40 \%$ selected freshness and 36\% price. Only 9\% cited chemical residues. Nevertheless, despite the relative low ranking that safety-related attributes have compared with eating quality attributes, $59 \%$ of respondents were buying vegetables with some form of assurance label.

Label awareness, understanding and recognition were also key elements affecting choice to purchase labelled vegetables. Most respondents exhibited a relatively low level of understanding and recognition of food safety labels. With the exception of the new Quality-Safety (QS) label, the greatest familiarity was with the Green Food and Organic Food labels for fresh produce. Of those consumers who did not buy assured produce, some $30 \%$ cited the additional costs, but almost $50 \%$ said that their usual retailer did not supply it. Indeed, it is generally only available in the city supermarkets. Hence accessibility to assured produce is determined by where consumers shop, although whether they then purchase it depends on other factors.

Trust is also a key element if consumers are to buy-in to assurance schemes and pay for enhanced food safety guarantees. Some $55 \%$ of respondents

\footnotetext{
${ }^{1}$ A 5 point Likert scale was in fact used for many questions in this instance for example ranging from "greatly concerned" to "not concerned at all". The results discussed above were compressed into 3 categories for ease of presentation - unconcerned, neutral and concerned.
}

expressed trust in labelled vegetables to guarantee safety and quality, although a minority of $12 \%$ distrusted labels. Another element of trust also resides in the retailer, although some $69 \%$ of respondents did not express trust in any retail outlet to sell safe vegetables, with minority of $22 \%$ trusting supermarkets above other outlets.

In questioning respondent WTP more, they were offered discrete choices of an additional $0 \%, 20 \%$, $40 \%, 50 \%, 80 \%$ and $100 \%$ for vegetables guaranteed in turn free of chemical residues, free of soil contaminants, free of pests, and free of genetic modification respectively and also for vegetables bearing either the Non-Pollution, or Green or Organic Food labels. The results were remarkably consistent with over $50 \%$ of respondents WTP $20 \%$ more for vegetables guaranteed free of chemical residues, or soil contaminants or pests. Concern with GM was less evident. Some $22 \%$ were also WTP $40 \%$ more for chemical residue free vegetables. Those consumers that did buy labelled vegetables were more likely to be WTP $40 \%$ more and less likely to select the $0 \%$ and $20 \%$ options compared with non-label purchasers. In other words, buyers of assured produce who by definition already pay more than for non-assured produce were willing to pay still more for guaranteed safe produce. However, there was no significant difference between the two groups at higher rates of WTP.

Whilst it was posited in Fig. 1 that education level could be a determinant of awareness and concerns about food safety issues which in turn would affect the propensity to buy assured vegetables, there was nevertheless a significant correlation $(\operatorname{Pr}<0.01)$ between respondents' incomes and education level (0.4). Hence, in the subsequent analyses, income was preferred as a possible explanatory variable to avoid collinearity problems in estimation.

Table 1 presents the SPSS $^{2}$ - derived maximum likelihood coefficient estimates of the binomial logit

\footnotetext{
${ }^{2}$ Statistical Package for the Social Sciences Version 17.
} 
function of whether consumers purchased labelled produce. Negative $\beta$ coefficients indicate a reduction in the logit or odds that the dependent variable $=1$, where 1 represents "buy labelled vegetables", and positive coefficients the converse. However the odds ratios $\left(\mathrm{e}^{\beta}\right)$ are perhaps more informative, and show that consumers who normally buy vegetables in wet-markets are only $60 \%$ as likely to buy label-assured vegetables. Although the coefficient is weakly significant, its inclusion improves the overall predictive performance of the model. Consumers with a monthly income of less than 3,000 RMB are only $30 \%$ as likely to buy labelled vegetables. In contrast, regular Beijing supermarket shoppers are almost three times as likely to buy labelled vegetables. However, it is worth observing that whilst it is necessary to shop in a supermarket to purchase labelled vegetables, there are nevertheless regular supermarket shoppers who do not buy labelled vegetables there. Trust in labels increases the odds ratio of buying almost 6-fold whilst trust in retailer almost doubles the probability of purchase. The overall predictive performance of the model is quite adequate correctly predicting $71 \%$ of non-buyers, $79 \%$ of buyers and $76 \%$ of all cases. ${ }^{3}$ Contrary to some earlier studies in provincial Chinese cities, this analysis has been unable to identify significant effects of gender or household size and composition on consumer purchasing behaviour for vegetables. It remains to be seen whether this is a specific capital-city feature when the analysis of the wider survey data from across other major cities in China is completed.

In analysing WTP, the study focuses on the most important consumer concern of chemical residues. However, in order to ensure a reasonable frequency of observations within the WTP categories, it was necessary to amalgamate some WTP categories. The

\footnotetext{
${ }^{3}$ A range of other variables including household composition, size, gender, vegetarianism, consumer concern over price were all tested in the model but were non-significant (though "price-concern" did exhibit a negative coefficient confirming a priori expectations).
}

final analysis was based on the WTP a price of $0 \%, 20 \%$ and $40 \%$ or greater for vegetables guaranteed free of residues. The ordinal multinomial logit polytomous universal model (PLUM) estimates are given in Table 2.

Where there are multiple-valued categorical exogenous variables, the $\beta$ coefficients and corresponding odds ratios were estimated relative to the highest level within the category. The $\chi^{2}$ test $^{4}$ of the likelihood ratios under the null hypothesis of common slope coefficients under different WTP response categories could not be rejected. Hence the ordinal rather than the multinomial (different slopes) model was selected as appropriate. This implies homogeneity of responses of consumers across all WTP categories, as opposed to differing response functions in each WTP category. All variables were significant at the 10 percent level or lower. The odds ratio for income and WTP declined sharply from the highest income category, with respondents in households of below 3,000 RMB monthly income only $7 \%$ as likely to pay more as those with over 10,000 RMB per month. Consumers with less concern over residues were only $30 \%$ as likely to pay more than those who expressed a high level of residue concern. Consumers who trusted labels, however, were 2.5 times more likely to be WTP more.Those who neither trusted the safety of vegetables in their main retail outlet or who chose to shop somewhere where the product quality was not assured were only $62 \%$ and $64 \%$ respectively as likely to pay more for residue free vegetables than those who were.

Table 3 presents the predictive performance of the model. Whilst less robust than the binomial model, it predicted $65 \%$ of all cases correctly. A comparison of predicted and actual individual WTP categories was of relatively similar orders of magnitude. However, whilst $80 \%$ of cases WTP $20 \%$ more, and $54 \%$ of those respondents WTP more than $40 \%$ were predicted

\footnotetext{
${ }^{4} \chi^{2}=8.47(\mathrm{pr}=0.39)$.
} 
Table1 Logit parameter estimates:purchase determinants ofassurance labelled vegetables.

\begin{tabular}{lllll}
\hline Variables in the Equation & $\beta$ & Standard error & Prob. & ${\text { Odds ratio } e^{\beta}}^{\beta}$ \\
\hline Buy in wetmarket & -0.51 & 0.33 & 0.12 & 0.60 \\
Buy in supermarket & 1.04 & 0.37 & 0.00 & 2.83 \\
Can main place of purchase guarantee safety? & 0.67 & 0.31 & 0.03 & 1.96 \\
Trust in Label & 1.78 & 0.29 & 0.00 & 5.94 \\
Income $<$ RMB 3,000 & -1.20 & 0.31 & 0.00 & 0.30 \\
Constant & -0.87 & 0.34 & 0.01 & 0.42 \\
$\mathrm{n}=$ & 319 & & & \\
-2 Log likelihood & 320.9 & & & \\
Model Predictive Performance: & & & & \\
Do you buy veg with labels? & & 71 & & \\
& No & 79 & & \\
\end{tabular}

Table 2 Ordinal multinomial parameter estimates of WTP for chemical residue-free vegetables.

\begin{tabular}{|c|c|c|c|c|c|}
\hline Variable & & Estimate $\beta$ & Std. error & Signif. & Odds ratioe $^{\beta}$ \\
\hline & Cut point WTP $0 \%$ & -5.12 & 0.89 & 0.00 & \\
\hline & Cut point WTP $20 \%$ & -1.83 & 0.86 & 0.03 & \\
\hline \multirow[t]{4}{*}{ Monthly Household Income RMB } & Below 3,000 & -2.83 & 0.80 & 0.00 & 0.06 \\
\hline & $3,000-4,999$ & -2.65 & 0.79 & 0.00 & 0.07 \\
\hline & $5,000-9,999$ & -1.44 & 0.80 & .07 & 0.24 \\
\hline & Above 10,000 & $0^{\mathrm{a}}$ & . & . & \\
\hline \multirow[t]{3}{*}{ Concern about Chemicals } & Low & -1.03 & 0.29 & 0.00 & 0.36 \\
\hline & Medium & -0.96 & 0.33 & 0.00 & 0.38 \\
\hline & High & $0^{\mathrm{a}}$ & . & . & \\
\hline \multirow[t]{2}{*}{ Distrust labels } & no & 0.93 & 0.37 & 0.01 & 2.54 \\
\hline & yes & $0^{\mathrm{a}}$ & . & . & \\
\hline Main purchase place guaranteessafety & no & -0.47 & 0.26 & 0.07 & 0.62 \\
\hline Safety & yes & $0^{\mathrm{a}}$ & . & $\cdot$ & \\
\hline \multirow[t]{2}{*}{ There is assured product quality and safety } & no & -0.45 & 0.27 & 0.09 & 0.64 \\
\hline & yes & $0^{\mathrm{a}}$ & . & . & \\
\hline
\end{tabular}

a. Parameter is set to zero because it is redundant.

Table 3 Predictive performance of ordinal multinomial WTP model.

\begin{tabular}{lllll}
\hline WTP Group & \multicolumn{3}{c}{ Predicted WTP Group Membership } \\
\hline $\mathbf{0 \%}$ & $0 \%$ & $20 \%$ & $\geq 40 \%$ & Actual \% \\
$\mathbf{2 0} \%$ & $26 \%$ & $67 \%$ & $7 \%$ & $8 \%$ \\
$\mathbf{4 0 \%}$ & $5 \%$ & $80 \%$ & $15 \%$ & $53 \%$ \\
Predicted Total \% & $2 \%$ & $44 \%$ & $54 \%$ & $39 \%$ \\
\hline $64 . \%$ of & $6 \%$ & $64 \%$ & $30 \%$ & \\
\hline
\end{tabular}

$64.9 \%$ of original grouped cases correctly classified.

correctly, the predictive ability for consumers unwilling to pay any extra was relatively poor, at $26 \%$. However, only some $8 \%$ of respondents fell into this category.

Of course, what consumers say they are WTP can differ from what they actually do pay. For HACCP certified milk, Wang et al. [19] established that consumers would pay around $10 \%$ extra on average though that study pre-dated the melamine contamination even and its aftermath. The study by 
Chang and $\mathrm{Li}$ [28] showed $80 \%$ of consumers in Nanjing WTP 20\% more for Green Food whilst Zhou [27] found consumers WTP $20 \%$ more for safe vegetables. This study based on a wealthier capital city revealed a somewhat greater degree of WTP for assurance labelling and guaranteed chemical residue free safety. Nevertheless, the model estimates confirm that acknowledged price-conscious Chinese consumers are generally unwilling to admit to being WTP very large price premiums for chemical residue-free vegetables. Paull [17] cited an actual Green Food price premium of the order of $10 \%-50 \%$. The results from this study fall within and at the upper end of that range.

\section{Conclusions}

If the safety of vegetables in China is to be improved, notwithstanding the existence and strengthening of minimum standards, it is important to identify the specific sources of consumer concerns, both to direct policy and consumer information, and to ensure that implementation is effective and consistent in order to allay them. Given that there is still a relatively overall low level of consumer understanding of traceability and recognition of some quality and safety assurance logos, clearly one area of focus needs to be on developing greater levels of public awareness of what such standards mean.

This study found that safety awareness and concerns are important elements in determining whether consumers buy assured and labelled produce and whether they were willing to pay more for additional guarantees concerning residues. The contribution of this paper has been in establishing the significance of these sources of concern, together with a range of socio-economic factors that bear on the WTP for safe vegetables, in quantifying their relative importance and the probability of their WTP a range of price premiums. In particular, the survey analysis demonstrated that trust was an important consideration for consumers, both in where they purchased their vegetables and in the integrity of assurance schemes and their labels. It also showed clearly that household income was a major determinant of the probability of consumers being WTP more for safer vegetables and to buy quality assured product.

Continuing food safety scandals in China since this research was completed will have doubtless highlighted and refocused consumer anxieties on issues of trust. Although these concerns have been met by strong responses from central government, the essence of trust will ultimately need to be founded not only on external guarantees and robust enforcement, but also on the implementation of the principles of "due diligence" by all participants in the supply chain in which all accept responsibility for food safety. To the extent that supermarkets are increasingly dominant in food retail in urban China, there is a likelihood of greater consumer accessibility to quality and safety-assured vegetables through the emergence of more integrated fresh produce supply chains.

\section{References}

[1] Van, D. M., and Pivonka, E. 2000. "Overview of the Health Benefits of Fruit and Vegetable Consumption for the Dietetics Professional: Selected Literature." J. Am. Diet Assoc. 12: 1511-21.

[2] Stan, S., and Kar, S., 2008. "Bioactive Food Components and Cancer Risk Reduction." J. Cell Biochem. 104: 339-56.

[3] Luedtke, A. N., and Chapman, B. 2003. "Implementation and Analysis of an On-Farm Food Safety Program for the Production of Greenhouse Vegetables." J. Food Protection 66: 485-9.

[4] Sivapalasingam, S., and Friedman, C. R. 2004. "Fresh Produce: A Growing Cause of Outbreaks of Foodborne Illness in the United States 1973 through 1997.” J. Food Protection 67: 2342-53.

[5] Steele, M., and Odumeru, J. 2004. "Irrigation Water as Source of Foodborne Pathogens on Fruit and Vegetables." J. Food Protection 67: 2839-49.

[6] Simonne, A. H., and Behe, B. K. 2006. "Consumers Prefer Low-Priced and High-Lycopene-Content Fresh-Market Tomatoes." Hort. Technol. 16: 674-81.

[7] Fröder, H., and Martins, C. G. 2007. "Minimally Processed Vegetable Salads: Microbial Quality 
Evaluation." J. Food Protection 70: 1277-80.

[8] Vanit-Anunchai, C., Schmidt, E., and Batt, P. J. 2006. "Consumer Purchase Decisions for Pesticide-Safe Vegetables Using Logistic Regression: The Case of Thailand.” Acta Horticulturae 699: 457-63.

[9] Lee, C. L., and Chiu, M. G. 2006. "Effects of Purchasing Behaviour and Choice Motivation of Consumers on Support Dried Mushroom Authentication." Nutritional Sciences J. 31: 59-67.

[10] Boccaletti, S., and Nardella, M. 2000. "Consumer Willingness to Pay for Pesticide-Free Fresh Fruit and Vegetables in Italy." International Food and Agribusiness Management Review 3: 297-310.

[11] Shi, M. 2008. Japanese Safety Standards of Imported Foods. Accessed August 6, 2004, http: info.worldbank.org/etools/docs/library/55383/china_efa2/ china_efa2/pdf/ppt_MinjunShi.pdf.

[12] Hamburger, J. 2006. "Pesticide Residues Still High in Chinese Vegetables." AP-Food Technology.com. Accessed August 12, 2008, http://www.ap-foodtechnology.com/Formulation/Pesticid e-residues-still-high-in-Chinese-vegetables.

[13] Xinhua, 2006. "Sixteen Diners Fall Sick after Eating Mushrooms in Beijing." China.org.cn. Accessed July 10, 2007, Xinhua.

[14] Zhou, J. H., and Zhong, Y. J. 2006. "The Vegetable Quality and Safety Management System in the US and Policy Implications for China." World Agriculture 1: 39-42. (in Chinese)

[15] Liu, Y., and Kong, G. T. 2007. "Effects of Soil Properties on Heavy Metal Accumulation in Flowering Chinese Cabbage in the Pearl River Delta, China." J. of Environmental Science and Health. Part. B 42: 219-27. (in Chinese)

[16] Wang, H. 2013. "Food Safety Tops Public's Concerns." China Daily.

[17] Paull,J.2008. "Green Food in China, Elementals." J. of Bio-Dynamics Tasmania 91: 48-53.

[18] Ortega, D. L., Wang, H., and Wu, L. 2009. "Food Safety and Demand: Consumer Preferences for Imported Pork in Urban China." J. of Food Distribution Studies 40 (3): 52-63.

[19] Wang, Z., Mao, Y., and Gale, F. 2008. "Chinese Consumer Demand for Food Safety Attributes in Milk Products." Food Policy 33: 27-36.

[20] Yang, X., and Qian, J. 2008. "Design and Application of a Safe Production and Quality Traceability System for
Vegetables." Nongye Gongcheng Xuebao (Transactions of the Chinese Society of Agricultural Engineering) 24: 162-6. (in Chinese)

[21] Shi, C. G., and Wang, K. 2011 "Analysis of Factors Affecting Consumers' Judgment of the Quality and Safety of Vegetables." Agriculture System Science and Comprehensive Study 27: 123-8. (in Chinese)

[22] Wang, E. P., and Zhou, Y. 2011 "Analysis of Urban Consumers' Trust of Certificated Vegetables and Influencing Factors.” Agriculture Technology Economy 11: 69-77. (in Chinese)

[23] Huang, J., and Qiu, H. 2006. "Awareness, Acceptance of and Willingness to Buy Genetically Modified Foods in Urban China." Appetite 46: 144-51.

[24] Misra, S., and Huang, C. H. 1991. "Consumer Willingness to Pay for Pesticide-Free Fresh Produce." Western J. of Agric. Econ. 16: 218-27.

[25] Li, B., and Ma, C. 2007. "Food Safety Assurance Systems in China." Food Control 18: 480-4. (in Chinese)

[26] Yang, J. and Zhang, G. 2004. "A Survey Report on the Market Price and Consumption Willingness of Pollution Vegetables in Shijiazhuang." Chinese Rural Economy 9: 43-8. (in Chinese)

[27] Zhou, J. H. 2004. “Analysis of Consumers's Afety Understanding, Attitudesand Purchasing Behaviour of Vegetables in Urban Jiangsu Province." Chinese Rural Economy. December, 44-52. (in Chinese)

[28] Chang, X., and Li, X. 2005. "The Study of Consumers' Awareness of Safe Vegetables in Nanjing." Consumer Economics 21: 72-6. (in Chinese)

[29] Dai, Y., and Zhu, B. 2006. 'Consumers' Choice on Food Safety: A Case Study of Organic Vegetable Purchasing Behavior in Nanjing." J. of Nanjing Agricultural University 6: 47-52. (in Chinese)

[30] Qing, P., and Yan, F. 2006. 'Consumers' Consuming Behaviours for Green Vegetables." Agricultural Economy 6: 73-8. (in Chinese)

[31] Zhou, Y. H., and Peng, X. J. 2006. "Consumer Willingness to Pay for Food Security in Jiangsu Province China: A Case Study of Reduced Pesticide Residues." China Economic Quarterly 5: 1319-42. (in Chinese)

[32] He, D., and Zhou, D. 2007. "The Consumption Behaviour for Pollution Free Vegetables in Wuhan." Statistics and Decision 6: 114-6. (in Chinese)

[33] McFadden, D. 1994. Conditional Logit Analysis of Qualitative Choice Behaviour.Edited by Zarembka, P., Frontiers of Econometrics, New York Academic Press. 